\title{
A method for quantitative measurement of lumbar intervertebral disc structures: an intra- and inter-rater agreement and reliability study
}

Andreas Tunset ${ }^{1}$, Per Kjaer ${ }^{1,2^{*}}$, Shadi Samir Chreiteh ${ }^{3}$ and Tue Secher Jensen ${ }^{2}$

\begin{abstract}
Background: There is a shortage of agreement studies relevant for measuring changes over time in lumbar intervertebral disc structures. The objectives of this study were: 1) to develop a method for measurement of intervertebral disc height, anterior and posterior disc material and dural sac diameter using MRI, 2) to evaluate intra- and inter-rater agreement and reliability for the measurements included, and 3) to identify factors compromising agreement.

Methods: Measurements were performed on MRIs from 16 people with and 16 without lumbar disc herniation, purposefully chosen to represent all possible disc contours among participants in a general population study cohort. Using the new method, MRls were measured twice by one rater and once by a second rater. Agreement on the sagittal start- and end-slice was evaluated using weighted Kappa. Length and volume measurements were conducted on available slices between intervertebral foramens, and cross-sectional areas (CSA) were calculated from length measurements and slice thickness. Results were reported as Bland and Altman's limits of agreement (LOA) and intraclass correlation coefficients (ICC).
\end{abstract}

Results: Weighted Kappa $\left(K_{w}(95 \%\right.$ Cl)) for start- and end-slice were: intra-: 0.82(0.60;0.97) \& 0.71 (0.43;0.93); inter-rater: 0.56 $(0.29 ; 0.78) \& 0.60(0.35 ; 0.81)$. For length measurements, LOA ranged from $[-1.0 ; 1.0] \mathrm{mm}$ to $[-2.0 ; 2.3] \mathrm{mm}$ for intra-; and from $[-1.1 ; 1.4] \mathrm{mm}$ to $[-2.6 ; 2.0] \mathrm{mm}$ for inter-rater. For volume measurements, LOA ranged from $[-293 ; 199] \mathrm{mm}^{3}$ to $[-582 ; 382] \mathrm{mm}^{3}$ for intra-, and from $[-17 ; 801] \mathrm{mm}^{3}$ to $[-450 ; 713] \mathrm{mm}^{3}$ for inter-rater. For CSAs, LOA ranged between $[-21.3 ; 18.8] \mathrm{mm}^{2}$ and $[-31.2 ; 43.7] \mathrm{mm}^{2}$ for intra-, and between $[-10.8 ; 16.4] \mathrm{mm}^{2}$ and $[-64.6 ; 27.1] \mathrm{mm}^{2}$ for inter-rater. In general, LOA as a proportion of mean values gradually decreased with increasing size of the measured structures. Agreement was compromised by difficulties in identifying the vertebral corners, the anterior and posterior boundaries of the intervertebral disc and the dural sac posterior boundary. With two exceptions, ICCs were above 0.81 .

Conclusions: Length measurements and calculated CSAs of disc morphology and dural sac diameter from MRIs showed acceptable intra- and inter-rater agreement and reliability. However, caution should be taken when measuring very small structures and defining anatomical landmarks.

Keywords: Magnetic resonance imaging, Intervertebral disc, Disc herniations, Measurement, Spinal canal, Dural sac, Agreement, Reliability, Limits of agreement, Intraclass correlation coefficient

\footnotetext{
* Correspondence: pkjaer@health.sdu.dk

'Department of Sports Science and Clinical Biomechanics, University of

Southern Denmark, Campusvej 55, Odense M DK-5230, Denmark

${ }^{2}$ Research Department, Spine Centre of Southern Denmark, Lillebaelt

Hospital, Oestre Hougvej 55, Middelfart DK-5500, Denmark

Full list of author information is available at the end of the article
} 


\section{Background}

In 1934, Mixter and Barr introduced the concept of lumbar disc herniations (LDH) as an explanation for radiating pain to the lower extremities [1,2]. Since then, extensive effort has been put into investigating the pathogenesis, clinical presentation, treatment and morphological changes involved in LDH [2]. LDH is generally regarded as a potential source of low back pain (LBP) and/or pain radiating to the leg, often below the knee [3]. In patients with clinical signs of nerve root compromise, about nine out of ten patients have disc-related findings on magnetic resonance imaging (MRI) [4]. On the other hand, LDH may be present without any pain or other clinical symptoms [5].

Dural sac size and intervertebral disc height have previously been found to be related to LDH, either clinically or biologically. The dural sac has a direct anatomical relationship with the intervertebral disc [6], and a direct mechanical influence is therefore possible due to an LDH taking up space in the spinal canal [7]. In addition, a correlation between a narrowed spinal canal and LBP and/or leg pain has been reported in cross-sectional studies [8-10]. Intervertebral disc height is possibly affected by LDH as material migrates posteriorly from the disc herniation. A study has shown a correlation between the classification of extended disc contour and disc height [11]. As there is evidence that disc height reduction is associated with LDHs and thus of potential clinical relevance, it was included in the current study.

Anterior disc material is similarly relevant, since it has been proposed that anterior LDHs may cause pain and symptoms [12,13]. Though this condition is rare, this imaging finding was also included in the current study, in order to be comprehensive.

Good long-term prognosis over a follow-up period of 6 months has been reported for a majority of people with LDH [14-17], and forms the current understanding of LDH among health care professionals $[18,19]$. In the context of clinical prognosis, it is relevant to know how LDHs change in size over time. Previous studies evaluating the change in size of LDHs over time have focused mainly on symptoms in clinical study populations [16,20-24]. Some studies have investigated the quantitative change in size of LDHs over time based on diagnostic imaging [25-29]. Three of these studies have reported the quantitative change in size over time of disc material relative to the spinal canal at multiple follow-ups [27-29], where measurements were based on a method developed by Kato et al. [27]. However, this method is described in insufficient detail to be replicated, due to the absence of definitions of anatomical boundaries.

For evaluation of disc changes over time, the ideal method is to use measurements from multiple image slices. The value of a multi-slice approach is that multiple length and area measurements can be combined into cross-sectional areas (CSA) or volumes, respectively, thereby increasing the chance of capturing changes that might otherwise be missed from single-slice methods. This multi-slice approach has been used in several studies [30-34]. It is also desirable that the method be described in sufficient detail to allow replication. Studies have provided method descriptions in varying detail [30,35-38] and in some cases, this detail is inadequate for replication.

Bland and Altman's Limits of Agreement (LOA) is the most popular [39], and recommended statistical method for evaluation of agreement [40-44]. The standard error of measurement (SEM) is similarly regarded as a suitable parameter of agreement [45], but is, however, sensitive to variability in the population [46]. Although a recent study reported use of LOA for evaluating agreement of measurements on intervertebral disc morphology [47], it is rarely used when evaluating agreement in the measurement of intervertebral discs, LDH, or the spinal canal [48].

No method for quantitatively measuring intervertebral discs, $\mathrm{LDH}$, and the dural sac was found in the literature that described in adequate detail a multi-slice technique and used LOA (Additional file 1). For a series of planned studies, we required a method to evaluate the changes in size over time of LDHs and their influence over time on dural sac size and intervertebral disc height, and their relationship with LBP. Therefore, we had need of a multi-slice technique for evaluating size of structures that was described in adequate detail and that used LOA to evaluate agreement.

The objectives of this study were:

1) to develop methods for quantitative measurement of anterior and posterior disc heights, extension of anterior and posterior lumbar disc material and dural sac diameter on MRI,

2) to evaluate the intra- and inter-rater agreement and reliability of the measurements included in these methods, and

3) to identify sources of measurement error in the measurement procedures.

\section{Materials and methods \\ Design}

The study is an intra- and inter-rater reliability study using repeated measurements of individual MRIs.

\section{Study population}

The sample of MRIs was selected from the longitudinal cohort-study entitled 'Backs on Funen, Denmark', which investigated potential risk factors for LBP. The Office of Civil Registrations sampled a cohort of 40-year old Danes in 2000. All subjects were from the general population living in the county of Funen, Denmark. One out 
of nine people in this age group was selected (625 individuals) and invited to participate by postal mail. People were excluded if they were severely disabled, had ferromagnetic implants, suffered from claustrophobia, or were not able to communicate in Danish [49]. From this cohort, 412 participated in 2001 at baseline and were re-invited to take part in 2005. At the second measurement of the cohort in 2005, 348 participated and were re-invited to take part in 2009. At the last measurement in 2009, 293 participated. At every measurement of the cohort, all participants had a lumbar MRI and filled in a questionnaire about their LBP. Permission for the original cohort study was granted by the local ethics committee (ref. no. 20000042) and the Danish Data Protection Agency (ref. no. 2000-53-0037) [49].

Sixteen participants assessed as having a disc herniation were purposefully selected by one of the co-authors not involved in the actual measurements (PK) to represent cases with all available types of disc herniations based on previous readings of the MRIs (see below). In the upper lumbar spine, LDH was found to be almost non-existent; therefore, we chose only the three lowest levels. A list of identification numbers, levels, types of herniation, and time of examination was generated and the sample was selected to be truly representative of all types of LDH. Sixteen other participants assessed as not having a disc herniation were randomly selected to participate in the agreement analysis as controls for comparison. Only one MRI per patient was selected among the three MRIs taken at the three available time-points.

\section{MRI}

MRI scans were performed with an open, low field $0.2 \mathrm{~T}$ magnetic resonance unit (Magnetom Open Viva, Siemens AG, Erlangen, Germany). The lumbar spine was scanned with participants in the supine position, using a combined body/surface coil. Sagittal T1- and T2-weighted and axial T2-weighted MRIs were performed with axial images placed in the plane of the five lower discs. The following sequences were performed at all three time-points:

- A localiser sequence of five images, 40/10/40 degrees (TR/TE/flip angle) consisting of two coronal and three sagittal images in orthogonal planes.

- Sagittal T1-weighted spin echo, 621/26 (TR/TE), $144 \times 256$ matrix, $300 \mathrm{~mm}$. FOV, 11 slices of $4 \mathrm{~mm}$. thickness, interslice gap of $0.8 \mathrm{~mm}$., 2 acquisitions, 6 min. 1 sec. scan time.

- Sagittal T2-weighted turbo spin echo 4609/134 (TR/effective TE), $210 \times 256$ matrix, $300 \mathrm{~mm}$. FOV, 11 slices of $4 \mathrm{~mm}$. thickness, interslice gap of 0.8 mm., 2 acquisitions, 8 min. 42 sec. scan time.

- Axial T2-weighted turbo spin echo 6415/134 (TR/effective TE), $180 \times 256$ matrix, $250 \mathrm{~mm}$. FOV,
3 slices of $5 \mathrm{~mm}$. thickness, interslice gap of 1.0 mm., 2 acquisitions, 7 min. 49 sec. scan time. Slices were placed in the plane of the five lower discs.

To account for scoliosis and vertebral rotation, the radiographers were instructed to align the sagittal images in the best way possible in all three planes. This meant that more than one sagittal series might have been performed in cases of serious scoliosis or vertebral rotation. For the purpose of this study, only the sagittal series that had the best alignment was used for measurement.

An experienced musculoskeletal radiologist evaluated the MRI scans of the lumbar spine from all three timepoints using a standardised evaluation protocol [50].

\section{Raters}

Inter-rater agreement was tested between two raters: one of whom was a student enrolled in a Master degree in clinical biomechanics (AT) who had no prior training in the interpretation of MRIs (Rater 1); the other was an experienced back pain researcher (TSJ) with extensive experience in interpreting MRIs for research purposes (Rater 2). These raters were purposely chosen to represent an inexperienced, and an experienced, interpreter of MRI. The intra-rater agreement was tested between measures performed by Rater 1 .

\section{Development of measurement method}

Various methods for measuring the anatomical structures from MRI investigated in the current study have been reported previously [7-10,30-38,48,51-72] (Additional file 1 ). None of these articles described an ideal method for detecting the longitudinal change in size of LDH. A new method was therefore developed based on knowledge from the literature and the experience of the authors (AT, PK \& TSJ).

Sagittal T2-weigthed MRIs were chosen for the measurements. We chose to use sagittal images because only three axial slices were available for each disc level in this study. The T2- rather than the T1-weighted sequence was chosen because of the increased contrast between the cerebrospinal fluid and the posterior part of the intervertebral disc and dural sac. Measures of length, cross-sectional area and volume were taken at the disc levels L3-L4, L4-L5 and L5-S1.

The following length measurements were defined: anterior and posterior intervertebral height (AIVH, PIVH), and the horizontal dimensions of the intervertebral disc (IVDL), anterior and posterior disc material extending beyond the corners of the vertebra (ADML, PDML) and dural sac. From these measures it was possible to calculate cross-sectional areas (CSAs): CSA of the anterior intervertebral height $(\mathrm{CAIH}), \mathrm{CSA}$ of the posterior intervertebral height $(\mathrm{CPIH}), \mathrm{CSA}$ of the intervertebral disc 
(CIVD), CSA of the anterior disc material (CADM), CSA of the posterior disc material (CPDM)s, and CSA of the dural sac (CDS). Furthermore, volume measurements were also defined for the anterior and posterior disc material that extended beyond the vertebral rim. The definitions of measurement parameters and descriptions of their mode of application are shown in Figure 1 and Table 1.

\section{Training of raters}

For the training sessions, 10 participants from the final data collection period, who were judged by the radiologist to have LDH only at this time point, were randomly selected for training. Prior to the actual agreement study, each rater reviewed the 10 cases independently, after which the cases were collectively reviewed and consensus reached on the measurement procedures.

\section{Measurements}

All measurements were evaluated for the appropriate disco-vertebral segments on each sagittal T2-image from the first left image with a visible pedicle (start slice) to the last right image with a visible pedicle (end slice), delineating the bottom and top of an intervertebral foramina (Figure 1). All images were magnified between $1100 \%-1200 \%$ during measurements, showing the relevant intervertebral disc horizontally on the screen. For brightness and contrast, default settings of images were used. Length measurements were conducted using the OsiriX 'length-tool'. Length measurements taken from all included sagittal MRIs from every structure were used for calculating the CSAs of those structures (Figures 1 and 2). Volume measurements were calculated by means of OsiriX measurement software using the 'pencil-tool' for manually tracing regions of interest (ROIs) from all slices on each sagittal image, and the 'Compute volume...' tool (Figures 2 and 3).

Insertion positions on the corners of the vertebrae were defined as the most anterior point for anterior corners, and the most posterior point for posterior corners. Possible osteophytes were regarded as part of the vertebral body, as delineation of these was challenging. Insertion positions on the boundaries between structures were defined by the point showing the most contrast between structures (Figure 1). The tracing of disc material areas, used for calculating volumes, was defined as the dark visual material located anteriorly or posteriorly to the already inserted line for disc height (Figure 3). Disc material protruding inferiorly or superiorly was included until visual delineation became indistinct, because alternative ways of distinguishing outlines of disc material and its segregation from adjacent longitudinal ligaments were all more challenging. A three-dimensional illustration of the approach for measuring and calculating structures is shown in Figure 2.

To avoid potential bias due to differences of equipment and software both raters used Apple 13" MacBooks with integrated touchpads. The free open-source measurement software OsiriX (version 4.1.2) was used by both raters. This version of OsiriX is designed for scientific use [73].

Data generated from length and volume measurements were stored as comma-separated values (CSV) files, using the OsiriX ROI plugin-tool 'export ROI'. CSV files were named with identification number, segment number, and the first and last section numbers of the MRI scan. In scans containing sections with fewer measurements of dural sac length, additional naming information was included. This naming added brackets following the initial

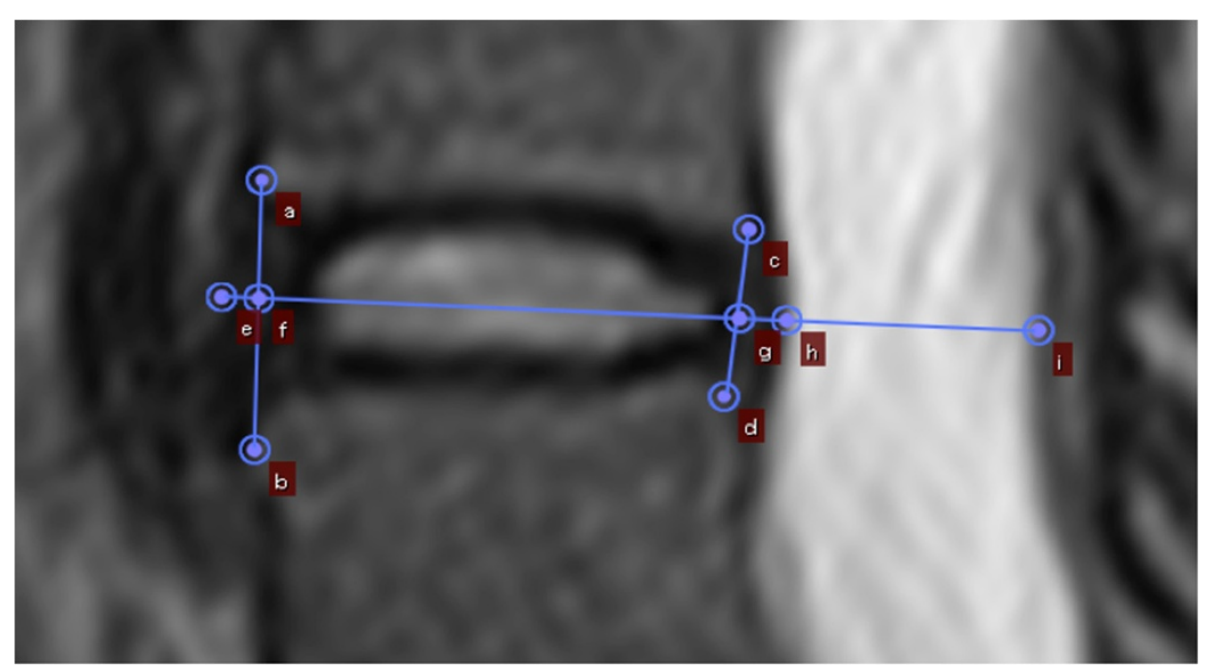

Figure 1 Positioning of measured structures (a-i); (a-b) Anterior intervertebral height; (c-d) Posterior intervertebral height; (e-f) Anterior disc material; (f-g) Intervertebral disc; (g-h) Posterior disc material; (h-i) Dural sac. 
Table 1 Abbreviations and definitions for measurement parameters

\section{Measurements \& calculation \\ Length measurements}

Anterior intervertebral height (AIVH)

Posterior intervertebral height (PIVH)

Intervertebral disc length (IVDL)

Anterior disc material length (ADML)

Posterior disc material length (PDML)

Antero-posterior dural sac length (ADSL)

\section{Cross-sectional area (CSA) calculation}

CSA of anterior intervertebral height (CAIH)

CSA of posterior intervertebral height $(\mathrm{CPIH})$

CSA of intervertebral disc (CIVD)

CSA of anterior disc material (CADM)

CSA of posterior disc material (CPDM)s

CSA of dural sac (CDS)

\section{Volume measurements}

Volume of anterior disc material (VADM)s

Volume of posterior disc material (VPDM)

\section{Definitions of measurement parameters}

Details of measurement execution

Distance between anterior-superior and anterior-inferio corners at vertebrae located at relevant intervertebral disc Distance between posterior-superior and posterior-inferio corners at vertebrae located at relevant intervertebral disc Distance between anterior and posterior boundaries of intervertebral disc

Distance between anterior and posterior boundaries of anterior herniated disc material

Distance between anterior and posterior boundaries of posterior herniated disc materia

Distance between anterior and posterior boundaries of dural sac

Sum of areas estimated by the product of length measurements of anterior intervertebral height, slice thickness, and inter-slice gap distance (Figure 2a)

Sum of areas estimated by product of length measurements of posterior intervertebral height, slice thickness, and interslice gap distance (Figure 2c)

Sum of areas estimated by product of length

measurements of intervertebral disc, slice thickness, and interslice gap distance (Figure $2 \mathrm{~b}$ )

Sum of areas estimated by product of length measurements of anterior disc material, slice thickness, and interslice gap distance Sum of areas estimated by product of length measurements of posterior disc material, slice thickness, and interslice gap distance (Figure 2d)

Sum of areas estimated by product of length measurements of dural sac, slice thickness, and interslice gap distance

Calculated volume of anterior disc material from tracing of sagittal areas in all slices

Calculated volume of posterior disc material from tracing of sagittal areas in all slices
OsiriX 'length-tool' between most anterior point at superior corner and most anterior corner at inferior corner (Figure 1: $a-b$ )

Osirix 'length-tool' between most posterior point at superior corner and most posterior corner at inferior corner (Figure 1: c-d)

OsiriX 'length-tool' between midway of AIVH and midway of PIVH (Figure 1: f-g)

OsiriX 'length-tool' between most anterior located boundary of anterio disc material and midway of AIVH. Linear continuation of IVDL (Figure 1: e-f)

OsiriX 'length-tool' between midway of PIVH and most posterior ocated boundary of posterior disc material. Linear continuation of IVDL (Figure 1: g-h)

Osirix 'length-tool' between most posterior located boundary of posterior disc material and most posterior located boundary of dural sac. Linear continuation of PDML (Figure 1: h-1)

Calculation of CSA using all slices for AIVH length measurements. (Additional file 2: Calculating software)

Calculation of CSA using all slices for PIVH length measurements. (Additional file 2: Calculating software)

Calculation of CSA using all slices for IVDL length measurements. (Additional file 2: Calculating software)

Calculation of CSA using all slices for ADML length measurements. (Additional file 2: Calculating software)

Calculation of CSA using all slices for PDML length measurements. (Additional file 2: Calculating software)

Calculation of CSA using all slices for ADSL length measurements. (Additional file 2: Calculating software)

OsiriX 'pencil-tool' tracing area of anterior disc material anterior of AIVH at all chosen slices. Osirix 'Compute volume...' tool for volume read-out (Figure 3: a)

OsiriX'pencil-tool' tracing area of posterior disc material posterior of PIVH at all chosen slices. Osirix 'Compute volume. ool for volume read-out (Figure 3: b) 


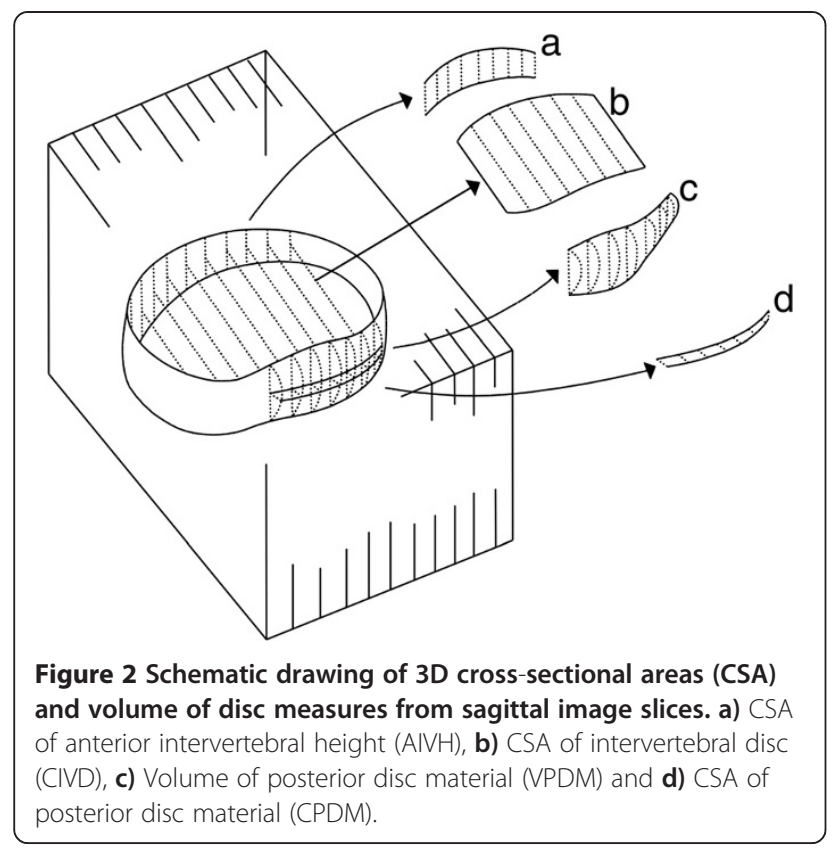

section's numbers containing missing dural sac identifiers. CSV files were further converted into XLSX files and converted into spread-sheets by customised software (Additional file 2) designed specifically for this study by an engineer (SSC) at the Institute of Sports Science and Clinical Biomechanics at the University of Southern Denmark, Odense, Denmark. The customised software calculated the length from the X, Y coordinates from the measurements. Calculation of CSA included the number of slices measured slice thickness, as well as the interslice gap. The
CSA of the anterior intervertebral height (CAIH) and the CSA of the posterior intervertebral height (CPIH) showed the CSA in the frontal plane and the remaining CSA in the axial plane (Figure 2).

Measurement data extracted by the custom-made software and stored in Excel were checked for consistency against the original ROI files supplied by OsiriX. All calculated results were screened for obvious errors by comparing them with the ROI files (Figure 4). Errors due to any altered order of measurements were manually corrected.

\section{Blinding}

To enhance the quality and applicability of the study, the raters were blinded in several ways [74]. Each rater was blinded to the findings of the other rater during measurements in the inter-rater analysis. In the intra-rater analysis, the rater was blinded to his own prior measurements. This was achieved by storing the data from the first measurement on a portable flash memory stick, which was stored by another project colleague. The order of participants was randomly changed between the two intra-rater measurement sessions. There was an 11-day interval between the first and second measurement sessions to lessen the likelihood of recognition of participants. All participants were anonymised for name, birth date, project ID, MRI access number, examination date, gender, and scan location.

\section{Data analysis}

An important issue when comparing measures is whether they are performed on the same slices. Therefore, we recorded all slice numbers and compared the raters' selections. The intra- and inter-rater agreement about the

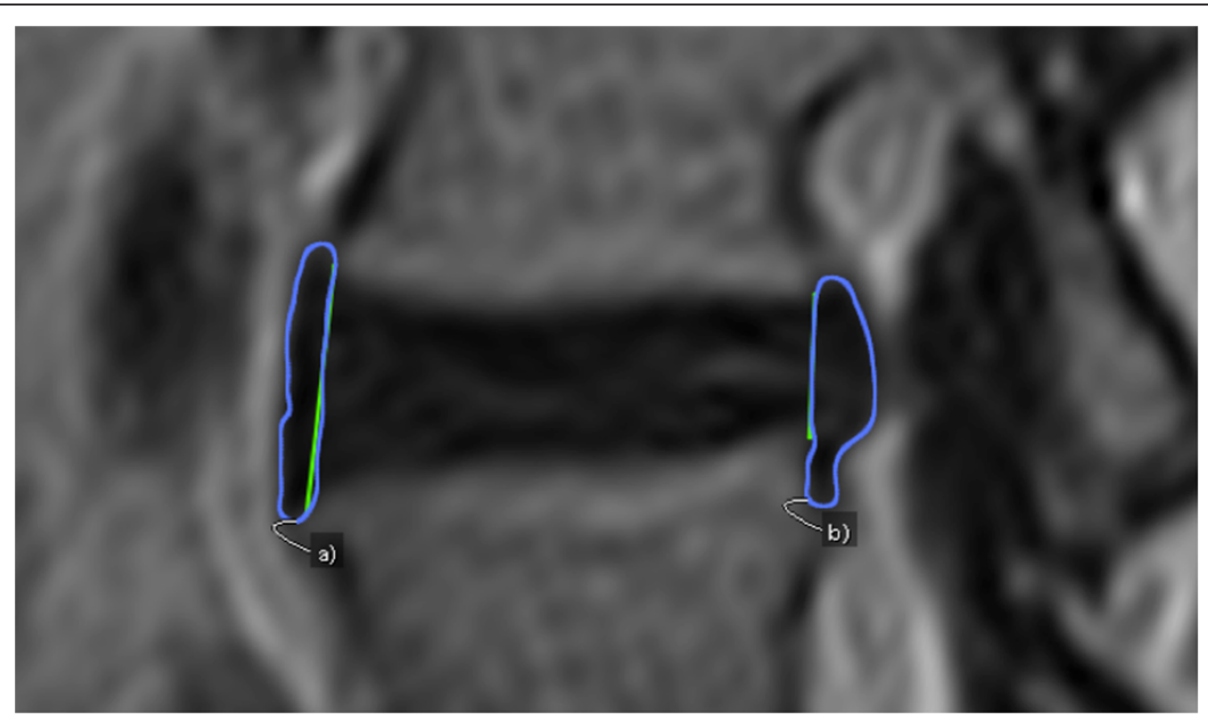

Figure 3 Illustration of outlining used for volume measurements. Outlining regions of interest in sagittal areas of a) anterior and $\mathbf{b})$ posterior disc material. Volume calculated from combined areas from all slices, slice thickness, and interslice gaps. The pre-set boundary between the vertebral corners and visual boundaries completes the outlining. 


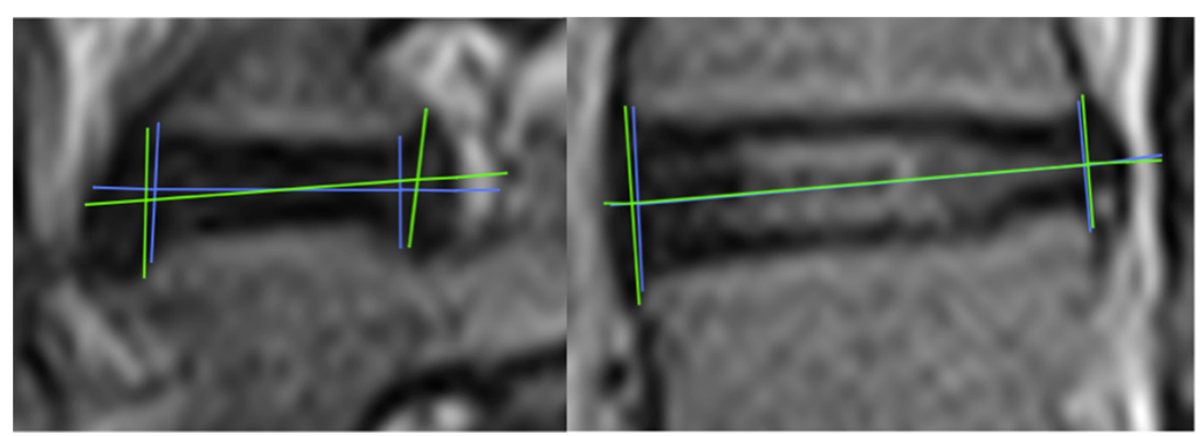

Figure 4 Examples of stored measurement images, used in data validation. Measurements stored as regions of interest during measurements were used for data validation. Single measurements were localised if needed and were checked against each other to ensure correct results. Images show a set of measurements with somewhat poor agreement between two measurements, and one with almost perfect agreement.

selection of the first $(1,2,3$ or 4$)$ and last slice $(6,7,8$ or 9) for measuring sagittal images (disc parameters and dural sac), were analysed using weighted Kappa statistics and reported as weighted Kappa coefficients $\left(K_{\mathrm{w}}\right)$ with 95\% CI. Since our focus was on the between-rater agreement of the measurements, we only compared measures that we performed on the same slice. For volume measurements and CSA calculations, the sets of data from all subjects where the start and end slice were not the same were excluded from the analysis.

The intra- and inter-rater agreement of the length and volume measurements, as well as the CSA calculations, were analysed using Bland \& Altman's [41] LOA. LOA is based on graphical techniques and simple calculations, and provides a plot of differences between the means of the measures, a bias shown as the mean difference, as well as the SD of the differences. This enables the calculation of $95 \%$ LOA to define ranges within which most differences between measures will lie (Figure 5). The 95\% CI was reported to describe the precision of the mean difference (bias). Bias was considered present if the 95\% CI did not include zero. Examples of good and poor results are given in Figures 6 and 7.

Furthermore, LOA were presented as a proportion of mean values for each structure. The proportion was calculated as follows: ((upper LOA $+\left(-1^{*}\right.$ (lower LOA))/the mean)*100. To the best of our knowledge, no reference standard for an acceptable cut-off proportion exists. Therefore, we arbitrarily considered percentages lower than 50\% as an indicator of acceptable precision.

Intra- and inter-rater reliability was evaluated with ICC type 2.1 [75]. These statistical analyses were conducted with STATA statistical software package Version 12.1 [76].

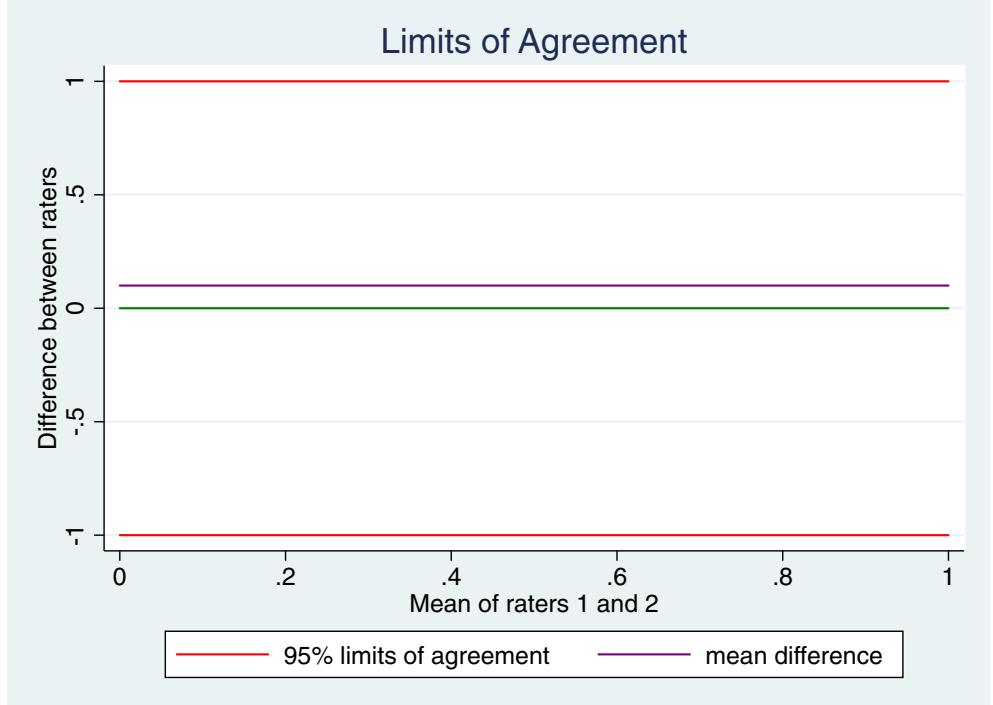

Figure 5 The Bland and Altman's plot. The $y$-axis shows the difference between raters' measurements, and the x-axis shows the mean value of both raters' measurements. The purple line shows the mean difference between measurements. Red lines show the $95 \%$ Limits of Agreement, between which $95 \%$ of all measurement differences are located. 


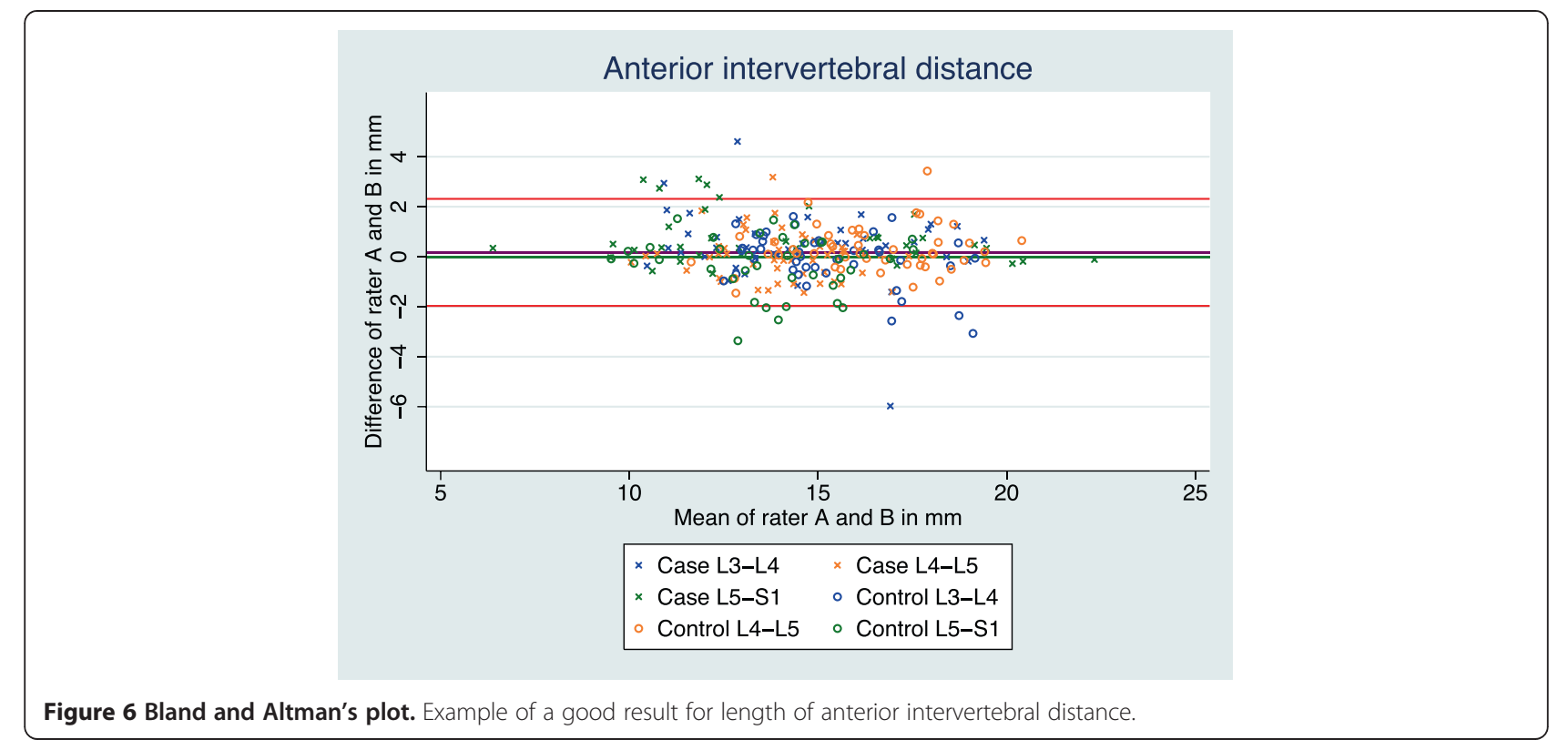

\section{Sample size considerations}

A Kappa power calculation using the formula $n=2 k^{2}$ from Haas et al. [77] for four response option categories estimated a required sample size of 32 participants. For each participant, approximately eight measurements were made for each structure.

A post hoc estimation of the precision of the LOA was also performed based on the formula suggested by Bland and Altman [41,78] and the standard deviations from the current study. Based on this, the 95\% CI for LOA was 0.21 times the standard deviation (SD) for the 257 length measurements (all $<0.26 \mathrm{~mm}$ ), 0.69 times the SD for the 24 intra-rater CSA calculations (all $<13.2 \mathrm{~mm}^{2}$ ), and 0.88 times the SD for the 15 inter-rater volume measurements (all $<262 \mathrm{~mm}^{3}$ ). These figures indicate the sample size to be sufficient for acceptable precision of LOA for the length measures and the CSA measures but not the volume measures.

According to Bonett, an approximate sample of 15 is needed for estimating ICC with an expected coefficient of 0.9 , an alpha level of $5 \%$, a width of 0.2 , and two categories [79]. The number of participants and measures exceeded that which was needed for satisfactory accuracy for evaluating reliability.

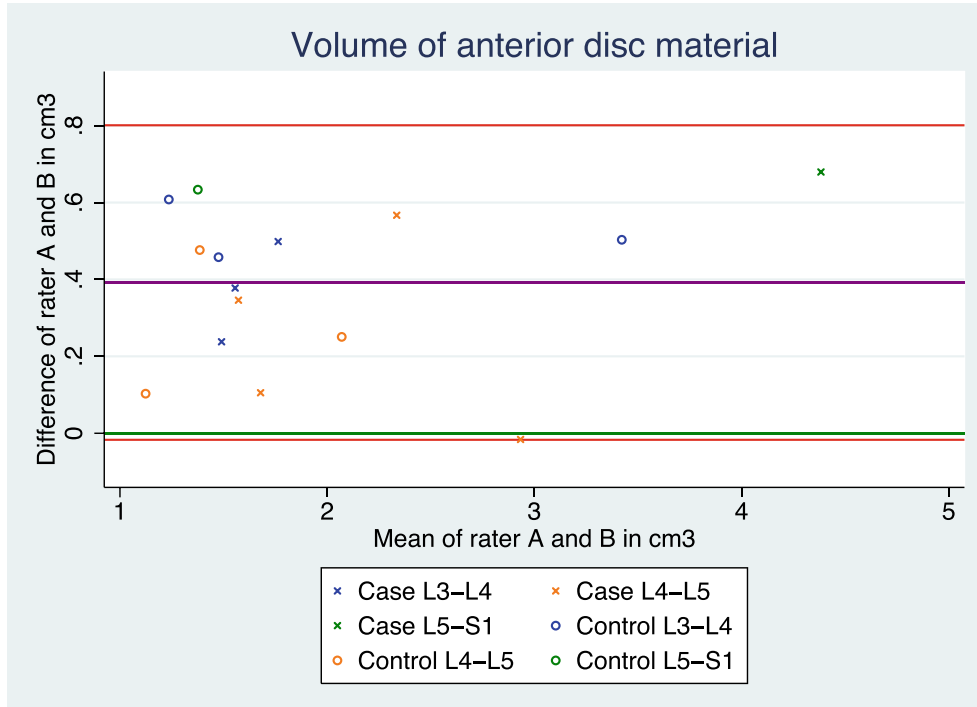

Figure 7 Bland and Altman's plot. Example of a poor result for volume of anterior disc material. 


\section{Factors that compromise agreement}

After analysis, the graphs depicting LOA were examined and outliers identified by visually distinguishing measurement differences that were far above or below the LOA on the graphs. These measurements were compared with the ROI files to identify possible reasons for 'out of range' measurements and reported in a narrative form. An example of comparison is given in Figure 4.

\section{Post hoc analysis}

Due to poor inter-rater agreement on the start- and endslices in the original analysis, a post-hoc re-analysis was undertaken. The definitions of the start- and end-slices were revised to include the requirement of visualisation of a full pedicle. This second inter-rater evaluation and weighted Kappa analysis of start- and end-slice for all structures, excluding the dural sac, were performed using the new criterion. Length and volume measurements were not repeated.

\section{Results}

Description of all measured parameters

In total, the lumbar MRIs from 32 participants were included in this study for evaluation of both intra- and inter-rater agreement and reliability. There were $17 \mathrm{fe}$ males and 15 males, all aged between 40 and 49 years. Of all the measurements conducted, 10 were on segment level L3-L4, 12 on segment level L4-L5 and 10 on segment level L5-S1. Of all the available posteriorly located disc materials, 12 were classified as normal, 4 as bulged 5 as focal protrusions, 5 as broad-based protrusions, 5 as extrusions and 1 as sequestration.

\section{Intra-rater agreement}

\section{Description of measured parameters}

For length measurements, 258 slices were included in the analysis for each parameter. For CSA calculations and volume measurements, 24 participants were included in the analysis for each parameter and eight participants were excluded due to differing numbers of slices. The exception was for CSA calculation for ADSL, which included 25 participants in the analysis and similarly excluded seven participants due to differing numbers of slices.

\section{Start- and end-slice on measurements}

Weighted Kappa for the choice of start-slice on dural sac length measurements was $\left(K_{w}(95 \% \mathrm{CI})\right): 0.84(0.65-0.97)$ and on remaining structures $\left(K_{\mathrm{w}}(95 \% \mathrm{CI})\right)$ : $0.82(0.60-$ $0.97)$ ). Weighted Kappa for the end-slice on dural sac length measurements was $\left(K_{w}(95 \% \mathrm{CI}): 0.87\right.$ (0.71 $0.97)$ and on all remaining structures was $\left(K_{w}(95 \% \mathrm{CI})\right.$ : $0.71(0.43-0.93))$. Cross tabulations are available in Additional file 3.

\section{Measurements of length}

The mean difference of all length measurements ranged between $-0.1 \mathrm{~mm}$ and $0.2 \mathrm{~mm}$, with $95 \%$ CI ranging between $-0.2 \mathrm{~mm}$ and $0.3 \mathrm{~mm}$. LOA ranged between [ -1.0 ; $1.0] \mathrm{mm}$ and $[-2.0 ; 2.3] \mathrm{mm}$, and between $6.8 \%$ and $62.9 \%$ of mean values (Table 2 and Additional file 4).

\section{Estimation of cross-sectional area}

The mean difference of all CSA calculations ranged between $-3.8 \mathrm{~mm}^{2}$ and $6.2 \mathrm{~mm}^{2}$, with $95 \% \mathrm{CI}$ ranging between $-11.5 \mathrm{~mm}^{2}$ and $14.3 \mathrm{~mm}^{2}$. LOA ranged between $[-21.3 ; 18.8] \mathrm{mm}^{2}$ and $[-31.2 ; 43.7] \mathrm{mm}^{2}$, and between $3.6 \%$ and $40.1 \%$ of mean values (Table 2 and Additional file 4).

\section{Measurements of volume}

Mean differences for both volume measurements were $-100 \mathrm{~mm}^{3}$ and $-47 \mathrm{~mm}^{3}$, with $95 \%$ CI ranging between $-204 \mathrm{~mm}^{3}$ and $6 \mathrm{~mm}^{3}$. LOA ranged between [293; 199] $\mathrm{mm}^{3}$ and $[-582 ; 382] \mathrm{mm}^{3}$, and between $37.3 \%$ and $45.1 \%$ of mean values (Table 2 and Additional file 4).

\section{Intra-rater reliability}

ICCs ranged from 0.90 (95\% CI 0.88-0.92) to 0.99 (0.991.00) for length measurements and from 0.95 (0.89-0.98) to 1.00 (1.00-1.00) for CSAs. ICCs for measurement of volume were $0.95(0.88-0.98)$ for anterior disc material and 0.95 (0.89-0.98) for posterior disc material (Table 3).

\section{Inter-rater agreement}

\section{Description of measured parameters}

For length measurements, 257 slices were included in the analysis for each parameter. For CSA calculations and volume measurements, 15 participants were included in the analysis for each parameter and 17 participants were excluded due to differing numbers of slices. The exception was the CSA calculation for ADSL, which included eight participants in the analysis and excluded 24 participants due to differing numbers of slices.

\section{Start- and end-slice for measurements}

Weighted Kappa for the choice of start-slice on dural sac length measurements was $\left(K_{w}(95 \% \mathrm{CI}): 0.22(0.08-0.42)\right.$ and on remaining structures was $\left(K_{w}(95 \% \mathrm{CI}): 0.35\right.$ (0.17 0.56)). Weighted Kappa for the choice of end-slice on dural sac length measurements was $\left(K_{w}(95 \% \mathrm{CI}): 0.22(0.05-\right.$ $0.43)$ and on all remaining structures $\left(K_{w}(95 \% \mathrm{CI}): 0.37\right.$ (0.08 - 0.66)). Post hoc analysis for start- and end-slice on all structures except dural sac showed weighted Kappa for start- $\left(K_{w}(95 \% \mathrm{CI}): 0.56(0.29-0.78)\right)$ and for end-slice $\left(K_{w}\right.$ (95\% CI): $0.60(0.35-0.81))$. Cross tabulations are available in Additional file 3. 
Table 2 Intra-rater measures agreement results

\begin{tabular}{|c|c|c|c|c|c|c|}
\hline Measurement & n (slices) & Mean $(\mathrm{mm})$ & $\begin{array}{c}\text { Standard } \\
\text { deviation }(\mathrm{mm})\end{array}$ & $\begin{array}{c}\text { Mean difference } \\
\text { (bias) }[95 \% \mathrm{Cl}](\mathrm{mm})\end{array}$ & $95 \%$ LOA $(\mathrm{mm})$ & $\begin{array}{l}\text { LOA as proportion } \\
\text { of mean values }(\%)\end{array}$ \\
\hline Length - AlVH & 258 & 14.7 & 1.1 & $0.2[0.0 ; 0.3]$ & $-2.0 ; 2.3$ & 29.3 \\
\hline Length - PIVH & 258 & 9.5 & 0.8 & $0.1[0.0 ; 0.2]$ & $-1.5 ; 1.6$ & 32.6 \\
\hline Length - IVDL & 258 & 31.1 & 0.5 & $-0.1[-0.1 ; 0.0]$ & $-1.1 ; 1.0$ & 6.8 \\
\hline Length - ADML & 258 & 3.5 & 0.6 & $0[-0.1 ; 0.1]$ & $-1.1 ; 1,1$ & 62.9 \\
\hline Length - PDML & 258 & 3.6 & 0.5 & $0[-0.1 ; 0.1]$ & $-1.0 ; 1.0$ & 55.6 \\
\hline \multirow[t]{2}{*}{ Length - ADSL } & 227 & 8.5 & 0.8 & $-0.1[-0.2 ; 0.0]$ & $-1.6 ; 1.4$ & 35.3 \\
\hline & n (participants) & $\left(\mathrm{mm}^{2}\right)$ & $\left(\mathrm{mm}^{2}\right)$ & $\left(\mathrm{mm}^{2}\right)$ & $\left(\mathrm{mm}^{2}\right)$ & $(\%)$ \\
\hline Area - CAlH & 24 & 512.6 & 19.1 & $6.2[-1.8 ; 14.3]$ & $-31.2 ; 43.7$ & 14.6 \\
\hline Area - CPIH & 24 & 327.6 & 11.7 & $4.5[-0.4 ; 9.4]$ & $-18.4 ; 27.4$ & 14.0 \\
\hline Area - CIVD & 24 & 1101.3 & 10.2 & $-1.2[-5.5 ; 3.1]$ & $-21.3 ; 18.8$ & 3.6 \\
\hline Area - CADM & 24 & 118.8 & 10.2 & $1[-3.3 ; 5.3]$ & $-19.0 ; 21.1$ & 33.8 \\
\hline Area - CPDM & 24 & 121.8 & 12.5 & $-1.6[-6.9 ; 3.7]$ & $-26.0 ; 22.8$ & 40.1 \\
\hline \multirow[t]{2}{*}{ Area - CDS } & 25 & 267.9 & 18.6 & $-3.8[-11.5 ; 3.9]$ & $-40.3 ; 32.7$ & 27.2 \\
\hline & & $\left(\mathrm{mm}^{3}\right)$ & $\left(\mathrm{mm}^{3}\right)$ & $\left(\mathrm{mm}^{3}\right)$ & $\left(\mathrm{mm}^{3}\right)$ & (\%) \\
\hline Volume - VADM & 24 & 2136.7 & 246 & $-100[-204 ; 4]$ & $-582 ; 382$ & 45.1 \\
\hline Volume - VPDM & 24 & 1314.8 & 126 & $-47[-100 ; 6]$ & $-293 ; 199$ & 37.4 \\
\hline
\end{tabular}

Number of slices measured for length, and participants measured for cross-sectional area and volume measurements, overall mean values, standard deviation, mean difference between measurements with $95 \%$ confidence intervals $(\mathrm{Cl}), 95 \%$ limits of agreement (LOA), and LOA as a proportion of mean values. Due to absence of dural sac at certain otherwise measured slices, a lower number of slices were measured. Participants with unequal start- and end-slices were excluded from the analyses, leading to varying numbers of included participants.

Table 3 Intra-rater measures reliability results

\begin{tabular}{ccc}
\hline Measurement & n (slices) & ICC [95\% Cl] \\
\hline Length - AIVH & 258 & $0.91[0.88,0.93]$ \\
Length - PIVH & 258 & $0.90[0.88,0.92]$ \\
Length - IVDL & 258 & $0.99[0.99,1.00]$ \\
Length - ADML & 258 & $0.95[0.94,0.96]$ \\
Length - PDML & 258 & $0.94[0.92,0.95]$ \\
Length - ADSL & 227 & $0.98[0.98,0.99]$ \\
& $\mathbf{n}$ (participants) & \\
Area - CAIH & 24 & $0.99[0.98,1.00]$ \\
Area - CPIH & 24 & $0.98[0.96,0.99]$ \\
Area - CIVD & 24 & $1.00[1.00,1.00]$ \\
Area - CADM & 24 & $0.97[0.94,0.99]$ \\
Area - CPDM & 24 & $0.95[0.89,0.98]$ \\
Area - CDS & 25 & $0.97[0.93,0.99]$ \\
Volume - VADM & 24 & $0.95[0.89,0.98]$ \\
Volume - VPDM & 24 & $0.95[0.88,0.98]$ \\
\hline
\end{tabular}

Number of slices measured for length and participants measured for crosssectional area and volume measurements, intraclass correlation coefficient (ICC), and accompanying 95\% confidence intervals (CI). Due to absence of dural sac at certain otherwise measured slices, a lower number of slices were measured. Participants with unequal start- and end-slices were excluded from the analyses, leading to varying numbers of included participants.

\section{Measurements of length}

The mean difference of all length measurements ranged between $-0.7 \mathrm{~mm}$ and $0.3 \mathrm{~mm}$, with $95 \%$ CI ranging between $-0.8 \mathrm{~mm}$ and $0.4 \mathrm{~mm}$. LOA ranged between [-1.1; 1.4] $\mathrm{mm}$ and $[-2.6 ; 2.0] \mathrm{mm}$, and between $9.7 \%$ and $105.9 \%$ of mean values (Table 4 and Additional file 4).

\section{Estimation of cross-sectional area}

The mean difference for all CSA calculations ranged between $-19.5 \mathrm{~mm}^{2}$ and $6.4 \mathrm{~mm}^{2}$, with $95 \% \mathrm{CI}$ ranging between $-31.7 \mathrm{~mm}^{2}$ and $19.7 \mathrm{~mm}^{2}$. LOA ranged between $[-10.8 ; 16.4] \mathrm{mm}^{2}$ and $[-64.6 ; 27.1] \mathrm{mm}^{2}$, and between $4.5 \%$ and $48.4 \%$ of mean values (Table 4 and Additional file 4).

\section{Measurements of volume}

Mean differences were $131 \mathrm{~mm}^{3}$ and $392 \mathrm{~mm}^{3}$, with $95 \%$ CI ranging between $-33 \mathrm{~mm}^{3}$ and $508 \mathrm{~mm}^{3}$. LOA ranged between $[-17 ; 801] \mathrm{mm}^{3}$ and $[-450 ; 713] \mathrm{mm}^{3}$, and between $44.7 \%$ and $104.1 \%$ of mean values (Table 4 and Additional file 4).

\section{Inter-rater reliability}

ICCs ranged from $0.73(0.69-0.79)$ to 0.98 (0.90-0.99) for length measurements and from $0.88(0.69-0.96)$ to 0.99 (0.97-1.00) for CSAs. ICCs for measurement of volume were $0.57(0.13-0.83)$ for anterior disc material and 0.90 (0.00-0.98) for posterior disc material (Table 5). 
Table 4 Inter-rater measures agreement results

\begin{tabular}{|c|c|c|c|c|c|c|}
\hline Measurement & n (slices) & Mean $(\mathrm{mm})$ & $\begin{array}{c}\text { Standard } \\
\text { deviation }(\mathrm{mm})\end{array}$ & $\begin{array}{c}\text { Mean difference } \\
\text { (bias) }[95 \% \mathrm{Cl}](\mathrm{mm})\end{array}$ & $\begin{array}{l}\text { 95\% Limits of agreement } \\
(\mathrm{LOA})(\mathrm{mm})\end{array}$ & $\begin{array}{c}\text { LOA as proportion of } \\
\text { mean values }(\%)\end{array}$ \\
\hline Length - AIVH & 257 & 14.9 & 1.2 & $-0.5[-0.7 ;-0.4]$ & $-2.8 ; 1.8$ & 30.9 \\
\hline Length - PIVH & 257 & 9.6 & 1.2 & $-0.3[-0.4 ;-0.2]$ & $-2.6 ; 2.0$ & 47.9 \\
\hline Length - IVDL & 257 & 31.2 & 0.8 & $-0.7[-0.8 ;-0.6]$ & $-2.2 ; 0.8$ & 9.7 \\
\hline Length - ADML & 257 & 3.4 & 0.6 & $0.1[0.0 ; 0.2]$ & $-1.1 ; 1.4$ & 73.6 \\
\hline Length - PDML & 257 & 3.4 & 0.9 & $0.3[-0.2 ; 0.4]$ & $-1.5 ; 2.1$ & 105.9 \\
\hline \multirow[t]{2}{*}{ Length - ADSL } & 229 & 8 & 1.1 & $0.2[0.0 ; 0.3]$ & $-2.0 ; 2.3$ & 53.8 \\
\hline & n (participants) & $(\mathrm{mm} 2)$ & $\left(\mathrm{mm}^{2}\right)$ & $\left(\mathrm{mm}^{2}\right)$ & $\left(\mathrm{mm}^{2}\right)$ & (\%) \\
\hline Area - CAlH & 15 & 568.2 & 23.4 & $-18.7[-31.7 ;-5.7]$ & $-64.6 ; 27.1$ & 16.2 \\
\hline Area - CPIH & 15 & 362.8 & 17.3 & $-13.3[-22.9 ;-3.7]$ & $-47.3 ; 20.7$ & 18.7 \\
\hline Area - CIVD & 15 & 1190.4 & 13.7 & $-19.5[-27.1 ;-11.9]$ & $-46.4 ; 7.4$ & 4.5 \\
\hline Area - CADM & 15 & 126.2 & 7 & $2.8[-1.1 ; 6.7]$ & $-10.8 ; 16.4$ & 21.6 \\
\hline Area - CPDM & 15 & 121.7 & 15 & $6.4[-2.0 ; 14.7]$ & $-23.1 ; 35.8$ & 48.4 \\
\hline \multirow[t]{2}{*}{ Area - CDS } & 8 & 286 & 17.8 & $4.8[-10.1 ; 19.7]$ & $-30.1 ; 39.8$ & 24.4 \\
\hline & & $\left(\mathrm{mm}^{3}\right)$ & $\left(\mathrm{mm}^{3}\right)$ & $\left(\mathrm{mm}^{3}\right)$ & $\left(\mathrm{mm}^{3}\right)$ & (\%) \\
\hline Volume - VADM & 15 & 1830.3 & 209 & $392[277 ; 508]$ & $-17 ; 801$ & 44.7 \\
\hline Volume - VPDM & 15 & 1117.6 & 297 & $131[-33 ; 296]$ & $-450 ; 713$ & 104.1 \\
\hline
\end{tabular}

Number of slices measured for length and participants measured for cross-sectional area and volume measurements, overall mean values, standard deviation, mean difference between measurements (bias) with $95 \%$ confidence intervals (CI), 95\% limits of agreement (LOA), and LOA as a proportion of mean values. Due to absence of dural sac at certain otherwise measured slices, a lower number of slices were measured. Participants with unequal start- and end-slices were excluded from the analyses, leading to varying numbers of included participants.

\section{Bias estimates}

The 95\% CI for mean differences suggested no statistically significant bias for intra-rater measures, and suggested a possible significant bias in a negative direction for seven out of 14 inter-rater parameters.

\section{Factors that compromise agreement}

A total of 27 outliers consisting of single intra-rater measurements and 20 outliers consisting of single inter-rater measurements were seen from the LOA plots. Three reasons were identified:

1) A different interpretation of vertebral corners at both the anterior and posterior locations, as well as superior and inferior locations was the reason for seven AIVH and PIVH outliers, nine IVDL outliers, one ADML outlier, and three PDML outliers. This may have been the reason for the IVDL and PDML outliers due to their dependence on AIVH and PIVH measurements.

2) Inconsistent distinction between structural boundaries due to lack of contrast was identified as inherent in three separate causes for outliers. The first was that five outliers were caused by a different interpretation of the anterior boundary of ADML. The second was that six outliers were caused by a different interpretation of the boundary between PDML and ADSL. The third was that fifteen outliers
Table 5 Inter-rater measures reliability results

\begin{tabular}{ccc}
\hline Measurement & n (slices) & ICC [95\% Cl] \\
\hline Length - AIVH & 257 & $0.88[0.82-0.92]$ \\
Length - PIVH & 257 & $0.81[0.76-0.85]$ \\
Length - IVDL & 257 & $0.98[0.90-0.99]$ \\
Length - ADML & 257 & $0.93[0.91-0.95]$ \\
Length - PDML & 257 & $0.73[0.64-0.79]$ \\
Length - ADSL & 229 & $0.96[0.95-0.97]$ \\
& $\mathbf{n}$ (participants) & \\
Area - CAIH & 15 & $0.96[0.81-0.99]$ \\
Area - CPIH & 15 & $0.93[0.68-0.98]$ \\
Area - CIVD & 15 & $0.99[0.78-1.00]$ \\
Area - CADM & 15 & $0.99[0.97-1.00]$ \\
Area - CPDM & 15 & $0.88[0.69-0.96]$ \\
Area - CDS & 8 & $0.95[0.79-0.99]$ \\
Volume - VADM & 15 & $0.90[0.00-0.98]$ \\
Volume - VPDM & 15 & $0.57[0.13-0.83]$
\end{tabular}

Number of slices measured for length and participants measured for crosssectional area and volume measurements, intraclass correlation coefficient (ICC), and accompanying 95\% confidence intervals (CI). Due to absence of dural sac at certain otherwise measured slices, a lower number of slices were measured. Participants with unequal start- and end-slices were excluded from the analyses, leading to varying numbers of included participants. 
were caused by a different interpretation of the posterior boundary of ADSL.

3) A single outlier for each of IVDL, ADML, PDML and ADSL was identified as an error in measurement execution. These errors were included in the CSAs and therefore influenced their results.

\section{Discussion}

This study reports a new method for measuring lumbar disc-related structures for use in research and in clinical practice. Intra-rater reliability in selecting start- and endslice was substantial and inter-rater reliability changed from poor to moderate after revision of the method [80]. The Bland and Altman's LOA showed very little bias (mean difference) and a small range for all intra-rater measurements and calculations. Reliability was high with most ICCs $>0.90$. For inter-rater measurements and calculations the Bland and Altman's LOA showed slightly higher bias and slightly higher ranges, with the exception of volume measurements, which had considerably larger bias and ranges. Reliability was slightly lower but most ICCs were $>0.73$. The uncertainty around volume measures was considerable. In general, LOA as a percentage of the mean values gradually decreased with increased size of the measured structures.

The results indicate that when measuring very small structures (e.g. ADML and PDML) on MRI, the changes over time have to be relatively large in order to detect changes. Combining length measures into volume measures reduces the LOA as a proportion of the mean. The measurement of volume by manual tracing seems to be dependent on the observer and the VPDM seems to be particularly problematic to agree upon.

The intra-rater measurements and calculations showed better agreement than inter-rater measurements, although the differences were not large. This indicates a good consensus regarding the anatomical delineation between length measurements by the same rater, but also acceptable consensus between the two raters. The same does not apply with volume measurements, where the inter-rater agreement was not acceptable. It seems the cumulative error in the marking of multiple anatomical structures was not accurate enough between multiple raters, resulting in differences that were unacceptably high. The same applies for start- and end-slice, where it seems agreement between raters is poor unless sufficient consensus on measurements is made beforehand. This appears to be due to difficulty in determining the slice delineating the boundary of the foramina, when using the criterion of visualisation of a fully visible pedicle, a criterion previously described in the literature [81].

Outliers found during the validation of the results could generally be traced to two main reasons: one being inexact positioning of vertebral corners; the other being difficulties in distinguishing between the anterior or posterior boundaries between structures. As for positioning of vertebral corners, a possible interfering factor could be the presence of osteophytes, by their modifying the visual appearance of the vertebra. For future use of this method, specification in advance of measurements, and persistent implementation of detailed definitions for aforementioned positionings, should be conducted by all raters. We were not able to find articles that definitively discussed any of these factors regarding similar problems with positioning or boundary distinction. Videman et al. [82] previously used a more thorough method for defining 'theoretical' vertebral corners. However, such an approach is likely to be more complicated and time-consuming.

A similar method of measuring the spinal canal was performed by Dora et al. [8]. They used sagittal MRIs and ICC and reported good inter-rater reliability (ICC >0.95). Other studies have used similar methods for measuring the spinal canal or the dural sac, but have not documented any kind of reproducibility $[9,28,63,68,69]$. A similar method is also used for measuring disc herniations and the spinal canal in some studies [27-29], but the method is described inadequately, and there is no reporting of analysis of agreement or reliability. One study performed similar quantitative measurements of similar structures on MRIs using LOA for determining agreement [48]. In this study, one finding on intervertebral disc length is comparable with the current study and indicates similar LOA. That study sample consisted of children and therefore their population was not directly comparable with ours. A study that compared results of MRIs in different positions showed anteriorly and posteriorly herniated disc material length measurements with almost exactly the same values [83]. A direct comparison with other studies is difficult, as this is the first study, to our knowledge, with the current statistical approach and such a detailed description of the method.

Agreement, together with reliability, is generally embedded in the expression reproducibility. In the literature, agreement and reliability are often used interchangeably, although their foci are different. Agreement focuses on measurement error when the focus is change in health status over time, while reliability is concerned with measurement error plus the variability between study objects and the focus is distinction between persons [45]. deVet et al. recommend reporting agreement parameters such as LOA, and further, when reporting reliability using ICC, they should be reported together with error estimates such as SEM [45]. This study uses both agreement and reliability, but the clear distinction between their use and meaning has been preserved.

Our review of the available literature (Additional file 1) showed a common pattern in methodological limitations through the use of inappropriate methods for longitudinal 
measurements, inadequate descriptions of methods, as well as unsatisfying statistical analyses of agreement. Out of 34 studies, only 17 reported reproducibility, and only one of these studies [48] used an appropriate statistical method - in that case, LOA. Eight of the remaining studies $[8,33,34,38,48,52,55,57]$ used ICC, which is a measure of reliability, not agreement [45]. Furthermore, only one out of these eight studies reported an error estimate [55].

We interpret our results as indicating that the measurement method used in this study is suitable for further use, with the exception of volume measurements. The method also makes it possible to validate data regarding errors made during measurements and those made during calculations, as well as indications for how to correct relevant errors in advance of the analysis. This data validation method may also be used for localising the reasons for outliers. As seen in the post-hoc analysis, a focus on consensus between raters is important for obtaining agreement about start- and end-slices. Our study is likely to be useful for future research because the method is appropriate for longitudinal measurements it contains a full and detailed description of the method and includes adequately conducted agreement and reliability analyses. In future studies and in clinical practice, this method can be used to detect changes larger than the LOA in disc morphology over time in individuals and between groups of patients. However, the size of the measure of interest has to be considered, since the relative precision increases with the size of the measurement (LOA as a percentage of the mean, Tables 2 and 4). In our research group, this method will form the basis for a series of research projects with the aims of investigating the changes in disc morphology over time and their association with clinical outcomes.

There could be a number of reasons for the observed poor agreement of inter-rater volume measurements. A possible explanation is a lack of certainty when manually tracing the anterior and posterior herniated disc material - an issue reported in earlier studies addressing volume measurements using MRIs [84,85]. Another explanation is a possible difficulty in separating herniated disc material from the longitudinal ligament, as these structures appear with almost the same signal intensity on MRI.

One limitation of this study may be the low resolution of the MRIs and the high magnification levels used. With a $144 \times 256$ matrix, $300 \mathrm{~mm}$ field of view and $4 \mathrm{~mm}$ slice thickness [49], the DICOM reader software digitally reconstructed the high detail of anatomical structures visible on the MRIs. This, in addition to the high magnification levels, increases the measurement precision but may reduce the accuracy of the image's representativeness of the actual anatomy. Any length measurement below the size of one voxel $(1.2$ (height) $\times 1.4$ (width) $\times$ 4.0 (depth) $\mathrm{mm}$ ) could therefore be considered relatively inaccurate. As for the length measurements of the anterior and posterior herniated disc material, there is a possibility that most of the anterior or posterior position is above or below the measured level, leading to possible underestimation of disc material sizes. Furthermore, as this study is not a test-retest study, it does not take into account the measurement errors that would be associated with repositioning patients, diurnal variations and the effect of activities within its estimates of intra- and inter-rater reliability.

The original study cohort was representative of the general population but the selection of a sample of cases and controls for the current study may affect the generalisability of the results. The reported means of measurements will not reflect those of the original cohort since only 22$25 \%$ in it had LDH. Although the prevalence of LDH, especially the more severe types, is likely to be higher in a clinical population, we believe that the measurement method will work in clinical populations. Our aim was to establish reproducibility and reliability, not to report prevalence or reference values for either a general or a clinical population.

It is possible that the ICCs and weighted Kappa values are inflated in this study, due to the large variability in the measures when purposefully selecting a sample representative of all types of $\mathrm{LDH}$ and of controls without LDH. The results may also be inflated by excluding a number of the more lateral MRI slices, when there was disagreement on start- and end-slice. The reason for this is that the LOA were relatively smaller for the larger structures. Another factor that may have increased the reproducibility and reliability is that only two raters were performing the measurements. However, when comparing ICCs in our study with those in other studies using the same measure of reliability, the results were very similar $[8,34,38]$.

In this study, we have performed several statistical analyses with an alpha level of $5 \%$ which by definition increases the risk of at least one chance finding in every twenty tests. However, the trends for the LOA and the ICCs are all in the same direction for the included measures. The variability in lumbar levels, LDH and normal discs in the study sample could lead to a suspicion that the LOA would be different for certain subgroups. However, in the Bland and Altman's LOA plots (Additional file 4), colours indicate the different levels as well as cases and controls. And when looking carefully at these, there are no obvious differences.

The strengths of this study are the high number of single length measurements, the carefully planned execution, the extensive review of the available literature as well as the well-described method. The high number of length measurements is also the basis for the CSAs. This study also followed a structured protocol from the 
beginning and adhered throughout to guidelines for studies of agreement $[44,74]$. Finally a comprehensive description of the method is available, as is the freeware measurement software [73]. This method also only takes 5 to 20 minutes per MRI to measure and interpret, depending on equipment, software preparation, and experience. In a clinical setting, a selection of relevant parameters such as CPDM, CPIH, and CDS may reduce the time consumption considerably.

\section{Conclusion}

This new method of quantifying length measurements of disc morphology and dural sac diameter from MRIs showed good intra- and inter-rater agreement as well as reliability. Quantitative volume measurements showed unacceptable agreement and reliability. However, caution should be taken when selecting start- and end-slice, measuring very small structures, and when defining anatomical landmarks. This method for quantitative measurement of lumbar intervertebral discs and related structures is suitable for testing in broader contexts, including in more diverse clinical samples, and in quantitative research that involves serial measurement of anatomical structures over multiple follow-up time periods.

\section{Additional files}

\section{Additional file 1: Literature review.}

Additional file 2: Description of calculating software (computer program available from the authors on request).

Additional file 3: Cross tabulations for start- and end-slices.

Additional file 4: Graphs of limits of agreement.

\section{Abbreviations}

ADML: Anterior disc material length; ADSL: Antero-posterior dural sac length; AIVH: Anterior intervertebral height; AT: Andreas Tunset; BSc: Bachelor of Science; CADM: Cross-sectional area of anterior disc material; CAlH: Crosssectional area of anterior intervertebral height; CDS: Cross-sectional area of dural sac; Cl: Confidence interval; CIVD: Cross-sectional area of intervertebral disc; CPDM: Cross-sectional area of posterior disc material; CPIH: Crosssectional area of posterior intervertebral height; CSA: Cross-sectional area; CSV: Comma separated values; DICOM: Digital imaging and communities in medicine; ICC: Intra-class correlation coefficient; ID: Identification;

IVDL: Intervertebral disc length; $K_{w}$ : Weighted Kappa; LBP: Low back pain; LDH: Lumbar Disc Herniation; LOA: Limits of agreement; MRI: Magnetic resonance imaging; MSc: Master of Science; PDML: Posterior disc material length; PhD: Doctor of Philosophy; PIVH: Posterior intervertebral height; PK: Per Kjaer; ROI: Region of interest; SSC: Shadi Samir Chreiteh; T: Tesla; TSJ: Tue Secher Jensen; VADM: Volume of anterior disc material; VPDM: Volume of posterior disc material.

\section{Competing interests}

There are no competing interests among authors.

\section{Authors' contributions}

AT, PK and TSJ developed the concept and design and administered the study, developed the method used in the study, performed the analysis and drafted the manuscript. AT and TSJ conducted all intra- and inter-rater measurements. SSC developed the software for calculating the data. AT drafted the manuscript. PK and TSJ reviewed the manuscript several times. All authors approved the manuscript in its final form.

\section{Authors' information}

An additional list of each author's qualifications and affiliations is available at the start of the article. This study is part of the undergraduate research education of a Master program in Clinical Biomechanics being undertaken by AT.

\section{Acknowledgements}

The Faculty of Health Sciences at The University of Southern Denmark granted a scholarship for execution of the undergraduate research education for AT. The Chiropractic Fund for Research and Postgraduate Education financially supported this study. The authors wish to thank Professor Tom Bendix for his role in designing the original study and securing primary funding from the Industrial Insurance Company, now Topdanmark. We also thank Professor Claus Manniche and The Spine Centre of Southern Denmark for hosting the entire project and, in particular, for making the third data collection possible by supplying secretarial support and providing imaging of the participants. Finally, we thank Annette Wille for completing the artwork for Figure 2.

\section{Author details}

'Department of Sports Science and Clinical Biomechanics, University of Southern Denmark, Campusvej 55, Odense M DK-5230, Denmark. ${ }^{2}$ Research Department, Spine Centre of Southern Denmark, Lillebaelt Hospital, Oestre Hougvej 55, Middelfart DK-5500, Denmark. ${ }^{3}$ DELTA, Venlighedsvej 4, Hørsholm DK-2970, Denmark.

Received: 30 January 2013 Accepted: 1 August 2013

Published: 16 August 2013

\section{References}

1. Mixter WJ, Barr JS: Rupture of the Intervertebral Disc with Involvement of the Spinal Canal. N Engl J Med 1934, 211(5):210-215.

2. Casey E: Natural history of radiculopathy. Phys Med Rehabil Clin N Am 2011, 22(1):1-5.

3. Konstantinou KDK: Sciatica - Review of epidemiological studies and prevalence estimates. Spine 2008, 33(22):2464-2472.

4. Jensen TS, Albert HB, Soerensen JS, Manniche C, Leboeuf-Yde C: Natural course of disc morphology in patients with sciatica - An MRI study using a standardized qualitative classification system. Spine 2006, 31(24):1605-1612.

5. Endean APK, Coggon D: Potential of magnetic resonance imaging findings to refine case definition for mechanical low back pain in epidemiological studies: a systematic review. Spine 2011, 36(2):160-169.

6. Renowden SA: Normal anatomy of the spinal cord. Pract Neurol 2012, 12(6):367-370.

7. Carragee EJ, Kim DH: A prospective analysis of magnetic resonance imaging findings in patients with sciatica and lumbar disc herniation. Correlation of outcomes with disc fragment and canal morphology. Spine (Phila Pa 1976) 1997, 22(14):1650-1660.

8. Dora C, Walchli B, Elfering A, Gal I, Weishaupt D, Boos N: The significance of spinal canal dimensions in discriminating symptomatic from asymptomatic disc herniations. Eur Spine J 2002, 11(6):575-581.

9. Visuri T, Ulaska J, Eskelin M, Pulkkinen P: Narrowing of lumbar spinal canal predicts chronic low back pain more accurately than intervertebral disc degeneration: a magnetic resonance imaging study in young Finnish male conscripts. Mil Med 2005, 170(11):926-930.

10. Pneumaticos SG, Hipp JA, Esses SI: Sensitivity and specificity of dural sac and herniated disc dimensions in patients with low back-related leg pain. J Magn Reson Imaging 2000, 12(3):439-443.

11. O'Neill C, Kurgansky M, Kaiser J, Lau W: Accuracy of MRI for diagnosis of discogenic pain. Pain physician 2008, 11(3):311-326.

12. Luoma K, Riihimaki H, Luukkonen R, Raininko R, Viikari-Juntura E, Lamminen A: Low back pain in relation to lumbar disc degeneration. Spine (Phila Pa 1976) 2000, 25(4):487-492.

13. Wong-Chung JK, Naseeb SA, Kaneker SG, Aradi AJ: Anterior disc protrusion as a cause for abdominal symptoms in childhood discitis. A case report. Spine (Phila Pa 1976) 1999, 24(9):918-920.

14. Weber $\mathrm{H}$, Holme I, Amlie $\mathrm{E}$ : The natural course of acute sciatica with nerve root symptoms in a double-blind placebo-controlled trial evaluating the effect of piroxicam. Spine (Phila Pa 1976) 1993, 18(11):1433-1438.

15. Saal JA, Saal JS: Nonoperative treatment of herniated lumbar intervertebral disc with radiculopathy. An outcome study. Spine (Phila Pa 1976) 1989, 14(4):431-437. 
16. Weber $\mathrm{H}$ : Lumbar disc herniation. A controlled, prospective study with ten years of observation. Spine (Phila Pa 1976) 1983, 8(2):131-140.

17. Hakelius A: Prognosis in sciatica. A clinical follow-up of surgical and non-surgical treatment. Acta orthopaedica Scandinavica Supplementum 1970, 129:1-76.

18. Jacobs WC, van Tulder M, Arts M, Rubinstein SM, van Middelkoop M, Ostelo $R$, Verhagen A, Koes B, Peul WC: Surgery versus conservative management of sciatica due to a lumbar herniated disc: a systematic review. Eur Spine J 2011, 20(4):513-522.

19. van Tulder M, Peul W, Koes B: Sciatica: what the rheumatologist needs to know. Nat Rev Rheumatol 2010, 6(3):139-145.

20. Suri P, Hunter DJ, Jouve C, Hartigan C, Limke J, Pena E, Li L, Luz J, Rainville J: Nonsurgical treatment of lumbar disk herniation: are outcomes different in older adults? J Am Geriatr Soc 2011, 59(3):423-429.

21. Weinstein JN, Lurie JD, Tosteson TD, Tosteson AN, Blood EA, Abdu WA, Herkowitz H, Hilibrand A, Albert T, Fischgrund J: Surgical versus nonoperative treatment for lumbar disc herniation: four-year results for the Spine Patient Outcomes Research Trial (SPORT). Spine 2008, 33(25):2789-2800.

22. Kohlboeck G, Greimel KV, Piotrowski WP, Leibetseder M, Krombholz-Reindl $M$, Neuhofer R, Schmid A, Klinger R: Prognosis of multifactorial outcome in lumbar discectomy: a prospective longitudinal study investigating patients with disc prolapse. Clin J Pain 2004, 20(6):455-461

23. Azimi P, Mohammadi HR, Montazeri A: An outcome measure of functionality and pain in patients with lumbar disc herniation: a validation study of the Japanese Orthopedic Association (JOA) score. J Orthop Sci 2012, 17(4):341-345.

24. Ng LC, Sell P: Outcomes of a prospective cohort study on peri-radicular infiltration for radicular pain in patients with lumbar disc herniation and spinal stenosis. Eur Spine J 2004, 13(4):325-329.

25. Saal JA, Saal JS, Herzog RJ: The natural history of lumbar intervertebral disc extrusions treated nonoperatively. Spine 1990, 15(7):683-686.

26. Modic MT, Obuchowski NA, Ross JS, Brant-Zawadzki MN, Grooff PN, Mazanec DJ, Benzel EC: Acute low back pain and radiculopathy: MR imaging findings and their prognostic role and effect on outcome. Radiology 2005, 237(2):597-604.

27. Kato F, Mimatsu K, Kawakami N, Iwata H, Miura T: Serial changes observed by magnetic resonance imaging in the intervertebral disc after chemonucleolysis. A consideration of the mechanism of chemonucleolysis. Spine 1992, 17(8):934-939.

28. Yukawa Y, Kato F, Matsubara Y, Kajino G, Nakamura S, Nitta H: Serial magnetic resonance imaging follow-up study of lumbar disc herniation conservatively treated for average 30 months: relation between reduction of herniation and degeneration of disc. J Spinal Disord 1996, 9(3):251-256.

29. Masui T, Yukawa Y, Nakamura S, Kajino G, Matsubara Y, Kato F, Ishiguro N: Natural history of patients with lumbar disc herniation observed by magnetic resonance imaging for minimum 7 years. J Spinal Disord Tech 2005, 18(2):121-126.

30. Malko JA, Hutton WC, Fajman WA: An in vivo magnetic resonance imaging study of changes in the volume (and fluid content) of the lumbar intervertebral discs during a simulated diurnal load cycle. Spine 1999, 24(10):1015-1022

31. Holodny Al, Kisza PS, Contractor S, Liu WC: Does a herniated nucleus pulposus contribute significantly to a decrease in height of the intervertebral disc? Quantitative volumetric MRI. Neuroradiology 2000, 42(6):451-454.

32. Violas $P$, Estivalèzes E, Pédrono A, Sales De Gauzy J, Sévely A, Swider P: A method to investigate intervertebral disc morphology from MRI in early idiopathic scoliosis: a preliminary evaluation in a group of 14 patients. Magn Reson Imaging 2005, 23(3):475-479.

33. Autio RA, Karppinen J, Niinimäki J, Ojala R, Kurunlahti M, Haapea M, Vanharanta $\mathrm{H}$, Tervonen O: Determinants of spontaneous resorption of intervertebral disc herniations. Spine 2006, 31(11):1247-1252.

34. Hamanishi C, Matukura N, Fujita M, Tomihara M, Tanaka S: Cross-sectional area of the stenotic lumbar dural tube measured from the transverse views of magnetic resonance imaging. J Spinal Disord 1994, 7(5):388-393.

35. Carlisle E, Luna M, Tsou PM, Wang JC: Percent spinal canal compromise on MRI utilized for predicting the need for surgical treatment in single-level lumbar intervertebral disc herniation. Spine J 2005, 5(6):608-614.

36. Zaaroor M, Kosa G, Peri-Eran A, Maharil I, Shoham M, Goldsher D: Morphological study of the spinal canal content for subarachnoid endoscopy. Minim Invasive Neurosurg 2006, 49(4):220-226.
37. Grams AE, Gempt J, Forschler A: Comparison of spinal anatomy between 3-Tesla MRI and CT-myelography under healthy and pathological conditions. Surg Radiol Anat 2010, 32(6):581-585.

38. Ogura H, Miyamoto K, Fukuta S, Naganawa T, Shimizu K: Comparison of magnetic resonance imaging and computed tomography-myelography for quantitative evaluation of lumbar intracanalar cross-section. Yonsei Med J 2011, 52(1):137-144.

39. Zaki R, Bulgiba A, Ismail R, Ismail NA: Statistical methods used to test for agreement of medical instruments measuring continuous variables in method comparison studies: a systematic review. PloS one 2012, 7(5):e37908

40. Hanneman SK: Design, analysis, and interpretation of methodcomparison studies. AACN Adv Crit Care 2008, 19(2):223-234.

41. Bland JM, Altman DG: Statistical methods for assessing agreement between two methods of clinical measurement. Lancet 1986, 1(8476):307-310.

42. McAlinden C, Khadka J, Pesudovs K: Statistical methods for conducting agreement (comparison of clinical tests) and precision (repeatability or reproducibility) studies in optometry and ophthalmology. Ophthalmic Physiol Opt 2011, 31(4):330-338.

43. Chatburn RL: Evaluation of instrument error and method agreement. AANA J 1996, 64(3):261-268.

44. Kottner J, Audige L, Brorson S, Donner A, Gajewski BJ, Hrobjartsson A, Roberts C, Shoukri M, Streiner DL: Guidelines for Reporting Reliability and Agreement Studies (GRRAS) were proposed. Int J Nurs Stud 2011, 48(6):661-671.

45. de Vet $\mathrm{HC}$, Terwee $C B, \mathrm{Knol} D L$, Bouter $L M$ : When to use agreement versus reliability measures. J Clin Epidemiol 2006, 59(10):1033-1039.

46. Atkinson G, Nevill AM: Statistical methods for assessing measurement error (reliability) in variables relevant to sports medicine. Sports Med 1998, 26(4):217-238.

47. Belavy DL, Armbrecht G, Felsenberg D: Evaluation of lumbar disc and spine morphology: long-term repeatability and comparison of methods. Physiol Meas 2012, 33(8):1313-1321.

48. Masharawi $Y$, Kjaer $P$, Bendix T, Manniche C, Wedderkopp N, Sorensen JS, Peled N, Jensen TS: The reproducibility of quantitative measurements in lumbar magnetic resonance imaging of children from the general population. Spine 2008, 33(19):2094-2100.

49. Kjaer P, Leboeuf-Yde C, Korsholm L, Sorensen JS, Bendix T: Magnetic resonance imaging and low back pain in adults: a diagnostic imaging study of 40-year-old men and women. Spine 2005, 30(10):1173-1180.

50. Solgaard Sorensen J, Kjaer P, Jensen ST, Andersen P: Low-field magnetic resonance imaging of the lumbar spine: reliability of qualitative evaluation of disc and muscle parameters. Acta Radiol 2006, 47(9):947-953.

51. Zhao L, Qu DB, Jin DD: Lumbar MRI measurement in normal adults and its clinical relevance. Chin J Clin Rehabil 2004, 8(20):4112-4113.

52. Cooley JR, Danielson CD, Schultz GD, Hall TA: Posterior disk displacement: morphologic assessment and measurement reliability-lumbar spine. J Manipulative Physiol Ther 2001, 24(5):317-326.

53. Alomari RS, Corso JJ, Chaudhary V: Labeling of lumbar discs using both pixel- and object-level features with a two-level probabilistic model. IEEE Trans Med Imaging 2011, 30(1):1-10.

54. Malko JA, Hutton WC, Fajman WA: An in vivo MRI study of the changes in volume (and fluid content) of the lumbar intervertebral disc after overnight bed rest and during an 8-hour walking protocol. J Spinal Disord Tech 2002, 15(2):157-163.

55. Lurie JD, Tosteson AN, Tosteson TD, Carragee E, Carrino JA, Kaiser J, Sequeiros RT, Lecomte AR, Grove MR, Blood EA: Reliability of magnetic resonance imaging readings for lumbar disc herniation in the Spine Patient Outcomes Research Trial (SPORT). Spine 2008, 33(9):991-998.

56. Violas P, Estivalezes E, Briot J, Sales de Gauzy J, Swider P: Objective quantification of intervertebral disc volume properties using MRI in idiopathic scoliosis surgery. Magn Reson Imaging 2007, 25(3):386-391.

57. Dora C, Schmid MR, Elfering A, Zanetti M, Hodler J, Boos N: Lumbar disk herniation: do MR imaging findings predict recurrence after surgical diskectomy? Radiology 2005, 235(2):562-567.

58. Zou J, Yang H, Miyazaki M, Wei F, Hong SW, Yoon SH, Morishita Y, Wang JC: Missed lumbar disc herniations diagnosed with kinetic magnetic resonance imaging. Spine 2008, 33(5):E140-144.

59. Puigdellivol-Sanchez A, Prats-Galino A, Reina MA, Maches F, Hernandez JM, De Andres J, van Zundert A: Three-dimensional magnetic resonance 
image of structures enclosed in the spinal canal relevant to anesthetists and estimation of the lumbosacral CSF volume. Acta anaesthesiologica Belgica 2011, 62(1):37-45

60. Pneumaticos SG, Chatziioannou AN, Hipp J, Chatziioannou SN: Prediction of successful discectomy using MRI quantitation of dural sac and herniated disc dimensions. Int J Clin Pract 2010, 64(1):13-18.

61. Chung SS, Lee CS, Kim SH, Chung MW, Ahn JM: Effect of low back posture on the morphology of the spinal canal. Skelet Radiol 2000, 29(4):217-223.

62. Lee GY, Lee JW, Choi HS, Oh KJ, Kang HS: A new grading system of lumbar central canal stenosis on MRI: an easy and reliable method. Skelet Radiol 2011, 40(8):1033-1039.

63. Hirasawa Y, Bashir WA, Smith FW, Magnusson ML, Pope MH, Takahashi K: Postural changes of the dural sac in the lumbar spines of asymptomatic individuals using positional stand-up magnetic resonance imaging. Spine 2007, 32(4):E136-140.

64. Grenier N, Kressel HY, Schiebler ML, Grossman RI, Dalinka MK: Normal and degenerative posterior spinal structures: MR imaging. Radiology 1987, 165(2):517-525.

65. Speciale AC, Pietrobon R, Urban CW, Richardson WJ, Helms CA, Major N, Enterline D, Hey L, Haglund M, Turner DA: Observer variability in assessing lumbar spinal stenosis severity on magnetic resonance imaging and its relation to cross-sectional spinal canal area. Spine 2002, 27(10):1082-1086.

66. Schizas C, Theumann N, Burn A, Tansey R, Wardlaw D, Smith FW, Kulik G. Qualitative grading of severity of lumbar spinal stenosis based on the morphology of the dural sac on magnetic resonance images. Spine 2010, 35(21):1919-1924

67. Madsen R, Jensen TS, Pope M, Sorensen JS, Bendix T: The effect of body position and axial load on spinal canal morphology: an MRI study of central spinal stenosis. Spine 2008, 33(1):61-67.

68. Knirsch W, Kurtz C, Haffner N, Langer M, Kececioglu D: Normal values of the sagittal diameter of the lumbar spine (vertebral body and dural sac) in children measured by MRI. Pediatr Radiol 2005, 35(4):419-424.

69. Jeong ST, Song HR, Keny SM, Telang SS, Suh SW, Hong SJ: MRI study of the lumbar spine in achondroplasia. A morphometric analysis for the evaluation of stenosis of the canal. J Bone Joint Surg Br Vol 2006, 88(9):1192-1196.

70. Jeffrey JE, Campbell DM, Golden MH, Smith FW, Porter RW: Antenatal factors in the development of the lumbar vertebral canal: a magnetic resonance imaging study. Spine 2003, 28(13):1418-1423.

71. Haig AJ, Weiner JB, Tew J, Quint D, Yamakawa K: The relation among spinal geometry on MRI, paraspinal electromyographic abnormalities, and age in persons referred for electrodiagnostic testing of low back symptoms. Spine 2002, 27(17):1918-1925. discussion 1924-1915.

72. Ahn TJ, Lee SH, Choi G, Ahn Y, Liu WC, Kim HJ, Lee HY: Effect of intervertebral disk degeneration on spinal stenosis during magnetic resonance imaging with axial loading. Neurologia medico-chirurgica 2009 49(6):242-247. discussion 247.

73. Osirix Imaging Software. http://www.osirix-viewer.com/license.pdf.

74. Lucas NP, Macaskill P, Irwig L, Bogduk N: The development of a quality appraisal tool for studies of diagnostic reliability (QAREL). J Clin Epidemiol 2010, 63(8):854-861.

75. Krebs DE: Declare your ICC type. Phys Ther 1986, 66(9):1431.

76. StataCorp: Stata Statistical Software. In Version 12 edn. Texas, USA: College Station; 2011.

77. Haas M: Statistical methodology for reliability studies. J Manipulative Physiol Ther 1991, 14(2):119-132.

78. How can I decide the sample size for a study of agreement between two methods of measurement?. http://www-users.york.ac.uk/ mb55/meas/ sizemeth.htm.

79. Bonett DG: Sample size requirements for estimating intraclass correlations with desired precision. Stat Med 2002, 21(9):1331-1335.

80. Landis JR, Koch GG: The measurement of observer agreement for categorical data. Biometrics 1977, 33(1):159-174.

81. Attias N, Hayman A, Hipp JA, Noble P, Esses SI: Assessment of magnetic resonance imaging in the diagnosis of lumbar spine foraminal stenosisa surgeon's perspective. J Spinal Disord Tech 2006, 19(4):249-256.

82. Videman T, Battie MC, Parent E, Gibbons LE, Vainio P, Kaprio J: Progression and determinants of quantitative magnetic resonance imaging measures of lumbar disc degeneration: a five-year follow-up of adult male monozygotic twins. Spine 2008, 33(13):1484-1490.
83. Parent EC, Videman T, Battie MC: The effect of lumbar flexion and extension on disc contour abnormality measured quantitatively on magnetic resonance imaging. Spine 2006, 31(24):2836-2842.

84. Prodhomme O, Seguret F, Martrille L, Pidoux O, Cambonie G, Couture A, Rouleau C: Organ volume measurements: comparison between MRI and autopsy findings in infants following sudden unexpected death. Arch Dis Child Fetal Neonatal Ed 2012, 97(6):F434-F438.

85. Shimada YJ, Shiota T: Underestimation of left atrial volume by threedimensional echocardiography validated by magnetic resonance imaging: a meta-analysis and investigation of the source of bias. Echocardiography 2012, 29(4):385-390.

doi:10.1186/2045-709X-21-26

Cite this article as: Tunset et al:: A method for quantitative measurement of lumbar intervertebral disc structures: an intra- and inter-rater agreement and reliability study. Chiropractic \& Manual Therapies 2013 21:26.

\section{Submit your next manuscript to BioMed Central and take full advantage of:}

- Convenient online submission

- Thorough peer review

- No space constraints or color figure charges

- Immediate publication on acceptance

- Inclusion in PubMed, CAS, Scopus and Google Scholar

- Research which is freely available for redistribution 